OPEN ACCESS

Edited by:

Aleksandra Barac

University of Belgrade, Serbia

Reviewed by:

Narendra Kumar,

National Institute of Mental Health and

Neurosciences (NIMHANS), India

Davies Adeloye,

University of Edinburgh,

United Kingdom

${ }^{*}$ Correspondence:

Ozren Polašek

ozren.polasek@mefst.hr

Specialty section:

This article was submitted to Infectious Diseases - Surveillance,

Prevention and Treatment,

a section of the journal

Frontiers in Public Health

Received: 12 May 2021

Accepted: 22 June 2021

Published: 27 July 2021

Citation:

Primorac D, Perić V, Matišić V, Molnar V, Zadro R, Vince A, Lauc G and Polašek O (2021) Rapid COVID-19 Antigen Testing in Croatia:

Risk Perception Plays an Important

Role in the Epidemic Control.

Front. Public Health 9:708907.

doi: 10.3389/fpubh.2021.708907

\section{Rapid COVID-19 Antigen Testing in Croatia: Risk Perception Plays an Important Role in the Epidemic Control}

\author{
Dragan Primorac 1,2,3,4,5,6,7,8,9 , Vitorio Perić ${ }^{1}$, Vid Matišić ${ }^{1}$, Vilim Molnar ${ }^{1,2}$, Renata Zadro ${ }^{1}$, \\ Adriana Vince ${ }^{10,11}$, Gordan Lauc ${ }^{12,13}$ and Ozren Polašek ${ }^{14 *}$ \\ ${ }^{1}$ St. Catherine Specialty Hospital, Zagreb, Croatia, ${ }^{2}$ School of Medicine, JJ Strossmayer University of Osijek, Osijek, Croatia, \\ ${ }^{3}$ Department of Pediatrics, University of Split School of Medicine, Split, Croatia, ${ }^{4}$ Eberly College of Science, The Pennsylvania \\ State University, University Park, State College, PA, United States, ${ }^{5}$ The Henry C. Lee College of Criminal Justice and \\ Forensic Sciences, University of New Haven, West Haven, CT, United States, ${ }^{6}$ Faculty of Dental Medicine and Health, School \\ of Medicine, University "Josip Juraj Strossmayer, Osijek, Croatia, ${ }^{7}$ Medical School, University of Rijeka, Rijeka, Croatia, \\ ${ }^{8}$ Medical School REGIOMED, Coburg, Germany, ${ }^{9}$ Medical School, University of Mostar, Mostar, Bosnia and Herzegovina, \\ ${ }^{10}$ University Hospital for Infectious Diseases Dr. Fran Mihaljević, Zagreb, Croatia, ${ }^{11}$ School of Medicine, University of Zagreb, \\ Zagreb, Croatia, ${ }^{12}$ Genos Ltd., DNA Laboratory, Zagreb, Croatia, ${ }^{13}$ Faculty of Pharmacy and Biochemistry, The University of \\ Zagreb, Zagreb, Croatia, ${ }^{14}$ Department of Public Health, University of Split School of Medicine, Split, Croatia
}

Aim: To explore the clinical presentation and epidemiological history of the subjects who underwent SARS-CoV-2 antigen testing.

Methods: We included 1,000 consecutive subjects who presented themselves at the diagnostic clinic in Croatia and analyzed their symptoms and epidemiological history. All subjects were classified into three groups, according to their reason of arrival; symptomatic, contacts of confirmed patients, and those who were tested due to administrative reasons.

Results: On average, there were $24 \%$ of positive antigen results; the positivity rate was $51 \%$ among symptomatic, $16 \%$ in contacts, and $5 \%$ of administrative patients. The commonest symptoms of the disease included febrility and anosmia. We developed a clinical score to predict SARS-CoV-2 positivity, which had an area under the curve of 79.3 [95\% confidence intervals (Cl) 75.8-82.8]. Contact with the isolated person [odds ratio $0.54(95 \% \mathrm{Cl} 0.31-0.94)]$ and international travel had a protective effect $[0.20$ (0.09-0.43)], suggesting that risk perception and mandatory pretravel measures had a key role in the determination of the infection risk.

Conclusions: A combination of clinical symptoms can have reasonable predictive power for an antigen-positive test result. Risk perception seems to have a role in the epidemic spread, probably via stricter adherence to personal preventative measures.

Keywords: SARS-CoV-2, risk, perception, antigen, diagnostic, pooling 


\section{INTRODUCTION}

The SARS-CoV-2 was discovered due to Wuhan viral pneumonia cases in 2019 and a pandemic was declared by the WHO on March 11, 2020. Common clinical signs of a person infected with SARS-CoV-2 include respiratory symptoms, fever, cough, shortness of breath, loss of smell and taste, and dyspnea (1). In more severe cases, the infection can cause bilateral pneumonia, severe acute respiratory syndrome, kidney failure, and even death (2). The SARS-CoV-2 virus is mainly transmitted via droplets generated by sneezing, coughing, and talking, as well as through contaminated hands since the virus can survive on various surfaces $(3,4)$. The diagnosis of COVID-19 encompasses clinical criteria, epidemiological history, and molecular detection of viral RNA in clinical samples. However, due to the growing number of people infected and tested positive on SARS-CoV-2 worldwide, it became necessary to develop easier, cheaper, and more available testing methods that could answer the need for increased testing. One of such methods is the rapid antigen test based on the direct detection of SARS-CoV-2 viral proteins in nasopharyngeal or nasal swabs using lateral flow immunoassay (5-7). The specificity of the antigen test is similar to the specificity of RT-PCR and ranges from 93.9 to $100 \%$, while sensitivity varies from 84.0 to $97.6 \%$ compared to RT-PCR $(8,9)$. Rapid tests are very informative for persons who have been in contact with confirmed patients with COVID-19 and are particularly useful for testing in higher-risk settings (nursing homes and student dormitories) when repetitive testing can easily detect persons with SARS$\mathrm{CoV}-2$ infection and prevent the spread of the infection. Even though rapid antigen tests are less sensitive than nucleic acid amplification tests, they provide results in approximately $15 \mathrm{~min}$ and present an excellent alternative and addition to the PCR testing (10).

This study aimed to analyze the association of symptoms and epidemiological history with the results of antigen testing and to explore the extent of clinical symptoms related to SARS-CoV2 infection.

\section{MATERIALS AND METHODS Study Design}

This was an observational study, based on the results of the COVID-19 antigen tests. The sample consisted of 1,000 consecutive subjects who presented themselves at the diagnostic clinic of the St. Catherine Specialty Hospital in Zagreb, Croatia. All the subjects were classified in one of three groups; symptomatic (who presented themselves with any combination of symptoms that might be associated with the COVID-19 disease), contacts of confirmed patients, and administrative reasons (which most commonly included a mandatory preoperative assessment). The subjects were recruited from October 2020-January 2021. All of the participants signed informed consent to participate in the study. The data for the study were based on unlinked testing results without any identifiable information, not requiring additional ethical approval.
TABLE 1 | Sample breakdown according to the group, age, and antigen testing results.

\begin{tabular}{lcccc}
\hline & $\begin{array}{c}\text { Symptomatic } \\
(\boldsymbol{n}=\mathbf{3 3 7})\end{array}$ & $\begin{array}{c}\text { Contacts } \\
(\boldsymbol{n}=\mathbf{2 9 1})\end{array}$ & $\begin{array}{c}\text { Administrative } \\
(\boldsymbol{n}=\mathbf{3 7 2})\end{array}$ & $\boldsymbol{P}$ \\
\hline $\begin{array}{l}\text { Age, years; } \\
\text { mean } \pm \text { SD } \\
{[\text { min-max] }}\end{array}$ & $\begin{array}{c}38.3 \pm 14.6 \\
{[1-79]}\end{array}$ & $\begin{array}{c}38.1 \pm 12.8 \\
{[3-78]}\end{array}$ & $\begin{array}{c}40.4 \pm 13.2 \\
{[5-83]}\end{array}$ & 0.059 \\
$\begin{array}{l}\text { Antigen- } \\
\text { positive; } n\end{array}$ & $171(50.7)$ & $47(16.2)$ & $18(4.8)$ & $<0.001$ \\
$(\%)$ & & & & \\
\hline
\end{tabular}

TABLE 2 | Reported symptoms in subjects with positive antigen test results, logistic regression.

\begin{tabular}{lcc}
\hline & $\boldsymbol{P}$ & OR [95\% Cl] \\
\hline Age & 0.033 & $1.01[1.00-1.03]$ \\
Fever & $\mathbf{0 . 0 0 1}$ & $\mathbf{5 . 9 4}[\mathbf{4 . 0 7 - 8 . 6 6}]$ \\
Sore throat & 0.209 & $1.42[0.82-2.43]$ \\
Loss of taste & 0.239 & $0.56[0.22-1.47]$ \\
Anosmia & $\mathbf{0 . 0 0 1}$ & $\mathbf{8 . 5 6}[\mathbf{3 . 8 6 - 1 8 . 9 9}]$ \\
Lack of energy & 0.840 & $1.07[0.54-2.13]$ \\
Fatigue & 0.373 & $0.71[0.33-1.51]$ \\
Cough & $\mathbf{0 . 0 0 9}$ & $\mathbf{1 . 8 8}[\mathbf{1 . 1 7}-\mathbf{3 . 0 3}]$ \\
Runny nose & 0.858 & $1.06[0.54-2.10]$ \\
Dyspnoea & 0.054 & $2.65[0.98-7.16]$ \\
Nausea & 0.111 & $0.25[0.05-1.37]$ \\
Diarrhoea & $\mathbf{0 . 0 0 5}$ & $\mathbf{0 . 1 1}[\mathbf{0 . 0 2 - 0 . 5 1 ]}$ \\
Vomit & 0.294 & $0.28[0.03-2.97]$ \\
Muscle pain & $\mathbf{0 . 0 0 7}$ & $\mathbf{2 . 3 1}[\mathbf{1 . 2 6 - 4 . 2 6}]$ \\
Headache & 0.039 & $1.65[1.03-2.65]$ \\
Back pain & 0.511 & $1.46[\mathbf{0 . 4 7 - 4 . 4 7 ]}$ \\
Chest pain & 0.337 & $0.49[0.12-2.10]$ \\
\hline
\end{tabular}

Significant values are provided in bold.

\section{Measurements}

To collect a nasopharyngeal swab sample, a sterile swab was inserted into the nostril of the patient, gently pushing the swab into the posterior nasopharynx and rotating against the nasal wall. After the sample collection, we used two rapid antigen tests with similar declared specificity and sensitivity (SARS-CoV2 Rapid Antigen Test, SD Biosensor, the Republic of Korea distributed by Roche Diagnostics GmbH, Germany and COVID19 Ag Test, von Minden GmbH, Germany). All tests were applied in accordance with the instructions of the manufacturer. The Ethical approval for the study was issued by the Ethical board of the Sv. Katarina hospital.

\section{Statistical Methods}

The numerical data were analyzed with $t$-test, while the categorical were analyzed with chi-square test. We also created a logistic regression model, which incorporated multiple predictor variables to analyze the symptoms or the leading epidemiological risks. We also developed a ROC curve, by using the lead results 
TABLE 3 | Exposures and risks for antigen positive test results, logistic regression.

\begin{tabular}{|c|c|c|c|c|}
\hline Predictor & \multicolumn{2}{|c|}{ Full model } & \multicolumn{2}{|c|}{ Excluded subjects who were ordered to self-isolate within the past 14 days } \\
\hline $\begin{array}{l}\text { Ever been in } \\
\text { self-isolation }\end{array}$ & 0.016 & $0.55[0.34-0.9]$ & 0.398 & $0.7[0.3-1.611]$ \\
\hline $\begin{array}{l}\text { Experienced } \\
\text { self-isolation within } \\
\text { past two weeks }\end{array}$ & $<0.001$ & $2.87[2.05-4.02]$ & & \\
\hline $\begin{array}{l}\text { Live with a person who } \\
\text { was positive }\end{array}$ & 0.716 & $1.09[0.69-1.73]$ & 0.240 & $1.43[0.79-2.584]$ \\
\hline $\begin{array}{l}\text { Contact with positive } \\
\text { person within past two } \\
\text { weeks }\end{array}$ & 0.740 & $0.93[0.59-1.46]$ & 0.948 & $1.02[0.58-1.803]$ \\
\hline $\begin{array}{l}\text { Contact with isolated } \\
\text { person within past } 2 \\
\text { weeks }\end{array}$ & 0.030 & $0.54[0.31-0.94]$ & 0.036 & $0.37[0.15-0.937]$ \\
\hline $\begin{array}{l}\text { International travel } \\
\text { within past two weeks }\end{array}$ & $<0.001$ & $0.20[0.09-0.43]$ & $<0.001$ & $0.21[0.09-0.501]$ \\
\hline $\begin{array}{l}\text { Hosmer-Lemeshow } \\
\text { test }\end{array}$ & 0.561 & & 0.603 & \\
\hline
\end{tabular}

of the logistic regression model, aiming to assess the clinical symptoms in the prediction of antigen test positivity. All the analyses were performed in $\mathrm{R}$, with significance set at $P<0.05$.

\section{RESULTS}

We included 1,000 consecutive subjects in this study, who have presented themselves at the diagnostic clinic. Among them, there were 337 symptomatic (33.7\%), 291 were contacts (29.1\%), while $372(37.2 \%)$ were tested for administrative reasons, most commonly due to preoperative protocol that included mandatory testing (37.2\%). Overall, the positivity rate was $23.6 \%$ on all tests. The breakdown according to the reason of testing yielded $50.7 \%$ positive antigen tests among the symptomatic subjects, $16.2 \%$ among contacts of people infected with SARS-CoV-2, and $4.8 \%$ of positive results in the group of subjects tested for administrative reasons. The three groups did not differ according to age, but subjects who were diagnosed for administrative reasons were insignificantly older (Table 1).

Positively tested subjects reported an interesting blend of symptoms, with the greatest odds ratios for anosmia, fever, muscle pain, and cough. Interestingly, diarrhea seemed to be inversely associated with the positive result on the SARS-CoV2 antigen test (Table 2). We then entered these four predictor variables in the score development, alongside age, which was also significant in the logistic regression model. The final model was created as the sum of binary results for the three significant symptoms, minus diarrhea, times age, or COVID score $=($ fever + cough + anosmia-diarrhoea ${ }^{*}$ age. The use of ROC indicated that the score had good predictive power, yielding an area under the curve of 79.3 [95\% CI 75.8-82.8].

The final analytic step was aimed at uncovering the epidemiological risks associated with the antigen-positive result. The first model that was used suggested that self-isolation within the past 2 weeks had the greatest odds of a positive result. In the subsequent model, we had excluded subjects who reported this (as they might have required a retesting after the self-isolation period had ceased). The reduced model suggested two significant results, contact with the isolated person within the past 2 weeks and international travel within the past 2 weeks; both models had a good fit, demonstrating a protective effect (Table 3 ).

\section{DISCUSSION}

The results of this study demonstrate that the combination of clinical symptoms can have a reasonable predictive power for an antigen-positive test result. In addition, these results show a substantial discrepancy of result outcomes in three groups of subjects. This finding is very interesting for increasing the effectiveness of the diagnostic process. The information on the a-priori chance for a positive result and population prevalence are critical for pooling, which aims to optimize the diagnostic procedures by reducing the cost of diagnostics. One of the most interesting results of this study is, therefore, the need for inclusion of information on the reason for testing to the actual testing process, knowing that certain pooling methods have the best savings in situations of low population prevalence, 
while their savings decrease as the population prevalence of the disease rises.

These results also show that risk perception plays a moderate but significant role in the antigen-confirmed disease status. This is to a degree moderated by the requirement for international travel (11-13), which is very strict and may elicit the need for multiple tests and strict adherence to personal protective equipment and epidemiological measures. Regardless of the modes of use, antigen testing is now established as a useful tool in diagnostic capabilities (14-16).

Clinical presentation of COVID-19-positive subjects was in line with previous studies, with cough, fever, and loss of smell being the most commonly reported symptoms (2). Interestingly, we have shown that diarrhea was inversely correlated with disease risk, which was in disagreement with a recent systematic review that had suggested that gastrointestinal symptoms were experienced by $13 \%$ of all patients (17). Although the ROC estimates in this study seem rather high, new approaches predicting critical patients have managed to yield even greater estimates (18).

The results of this study must be considered within the wider-sense societal epidemiological situation, marked by the strict initial quarantine and favorable population response in the early epidemic stages $(19,20)$. It could be argued that the epidemic dynamics may affect the situation, therefore, the results obtained here might not be relevant for all time points of the epidemic; this was already identified in the past, suggesting the need for constant monitoring and provision of timely-sensitive data for decision making (20). Additionally, the sample composition is also a possible source of bias, including the patients who presented themselves in the private clinic, preventing generalizability to the entire population. Nevertheless, the results do show that the diagnostic process should include clinical information, and not be completely unlinked. This may increase the effectiveness of the diagnostic process, by the ability to employ pooling in favorable instances (21). A better understanding of the risk determinants and improvements of the diagnostic process are the key components of reactive epidemic management.

\section{REFERENCES}

1. Giacomelli A, Pezzati L, Conti F, Bernacchia D, Siano M, Oreni L, et al. Selfreported olfactory and taste disorders in patients with severe acute respiratory coronavirus 2 infection: a cross-sectional study. Clin Infect Dis. (2020) 71:88990. doi: $10.1093 / \mathrm{cid} /$ ciaa330

2. $\mathrm{Wu} \mathrm{Z}, \mathrm{McGoogan} J \mathrm{M}$. Characteristics of and important lessons from the coronavirus disease 2019 (COVID-19) outbreak in china: summary of a report of 72314 cases from the Chinese center for disease control and prevention. JAMA. (2020) 323:1239-42. doi: 10.1001/jama.2020.2648

3. van Doremalen N, Bushmaker T, Morris DH, Holbrook MG, Gamble A, Williamson BN, et al. Aerosol and surface stability of SARS-CoV2 as compared with SARS-CoV-1. N Engl J Med. (2020) 382:1564-67. doi: 10.1056/NEJMc2004973

4. Kampf G, Todt D, Pfaender S, Steinmann E. Persistence of coronaviruses on inanimate surfaces and their inactivation with biocidal agents. J Hosp Infect. (2020) 104:246-51. doi: 10.1016/j.jhin.2020.01.022

\section{DATA AVAILABILITY STATEMENT}

The raw data supporting the conclusions of this article will be made available by the authors, without undue reservation.

\section{ETHICS STATEMENT}

The studies involving human participants were reviewed and approved by Ethical board of the Sv. Katarina Hospital. The patients/participants provided their written informed consent to participate in this study.

\section{AUTHOR CONTRIBUTIONS}

VP, VMa, VMo, RZ, GL, and DP conceived the study and designed the study in collaboration. OP analyzed the data. VP, VMa, VMo, AV, and RZ wrote the first draft of the manuscript. OP and DP critically revised the manuscript. All the authors interpreted the data and contributed to subsequent drafts of the manuscript, and all the authors have seen and approved the final version.

\section{FUNDING}

This study was funded by the Croatian National Centre of Research Excellence in Personalized Healthcare grant (number KK.01.1.1.01.0010), and the Centre of Competence in Molecular Diagnostics (KK.01.2.2.03.0006).

\section{ACKNOWLEDGMENTS}

We thank the medical staff at St. Catherine Specialty Hospital who were quick to respond to the global need for joint medical action to combat the pandemic, namely: Marina Žanić, Tamara Štivić, Tihana Benčić, Darija Marušić, Milica Tepavac, Svjetlana Mijatović, Andela, Ana-Marija Fiket, Ivanka Mesar, Jelena Pavlović, Jere Bilić, and Krunoslav Štefančić who were responsible for obtaining the samples.

5. Nordgren J, Sharma S, Olsson H, Jämtberg M, Falkeborn T, Svensson L, et al. SARS-CoV-2 rapid antigen test: High sensitivity to detect infectious virus. $J$ Clin Virol. (2021) 140:104846. doi: 10.1016/j.jcv.2021.104846

6. Peña M, Ampuero M, Garcés C, Gaggero A, García P, Velasquez MS, et al. Performance of SARS-CoV-2 rapid antigen test compared with real-time RT-PCR in asymptomatic individuals. Int J Infect Dis. (2021) 107:201-4. doi: 10.1101/2021.02.12.21251643

7. Colavita F, Vairo F, Meschi S, Valli MB, Lalle E, Castilletti C, et al. COVID19 Rapid antigen test as screening strategy at points of entry: experience in lazio region, central italy, August-October 2020. Biomolecules. (2021) 11:425 doi: 10.3390/biom11030425

8. Porte L, Legarraga P, Vollrath V, Aguilera X, Munita JM, Araos R, et al. Evaluation of a novel antigen-based rapid detection test for the diagnosis of SARS-CoV-2 in respiratory samples. Int J Infect Dis. (2020) 99:328-33. doi: $10.1016 /$ j.ijid.2020.05.098

9. CDC. Interim Guidance for Rapid Antigen Testing for SARS-CoV-2. Atlanta, GA: CDC (2020). 
10. Mak GC, Cheng PK, Lau SS, Wong KK, Lau CS, Lam ET, et al. Evaluation of rapid antigen test for detection of SARS-CoV-2 virus. J Clin Virol. (2020) 129:104500. doi: 10.1016/j.jcv.2020.104500

11. Allgöwer A, Aebischer Perone S, Schibler M, Schwob JM, D'Acremont V, Chappuis F, et al. [SARS-CoV-2 screening in travelers: what approach to assess transmission risk?]. Rev Med Suisse. (2021) 17:866-70.

12. Viswanathan M, Kahwati L, Jahn B, Giger K, Dobrescu AI, Hill C, et al. Universal screening for SARS-CoV-2 infection: a rapid review. Cochrane Database Syst Rev. (2020) 9:CD013718. doi: 10.1002/14651858.CD01 3718

13. Burns J, Movsisyan A, Stratil JM, Coenen M, Emmert-Fees KM, Geffert $\mathrm{K}$, et al. Travel-related control measures to contain the COVID-19 pandemic: a rapid review. Cochrane Database Syst Rev. (2020) 10:CD013717. doi: 10.1002/14651858.CD013717

14. Kotsiou OS, Pantazopoulos I, Papagiannis D, Fradelos EC, Kanellopoulos N, Siachpazidou D, et al. Repeated antigen-based rapid diagnostic testing for estimating the coronavirus disease 2019 prevalence from the perspective of the workers' vulnerability before and during the lockdown. Int J Environ Res Public Health. (2021) 18:1638. doi: 10.3390/ijerph18041638

15. McKay SL, Tobolowsky FA, Moritz ED, Hatfield KM, Bhatnagar A, LaVoie SP, et al. Performance evaluation of serial SARS-CoV-2 rapid antigen testing during a nursing home outbreak. Ann Intern Med. (2021) M21-0422. doi: 10.7326/M21-0422. [Epub ahead of print].

16. Dinnes J, Deeks JJ, Berhane S, Taylor M, Adriano A, Davenport $\mathrm{C}$, et al. Rapid, point-of-care antigen and molecular-based tests for diagnosis of SARS-CoV-2 infection. Cochrane Database Syst Rev. (2021) 3:CD013705. doi: 10.1002/14651858.CD013705. pub2

17. Dorrell RD, Dougherty MK, Barash EL, Lichtig AE, Clayton SB, Jensen ET. Gastrointestinal and hepatic manifestations of COVID-19: A systematic review and meta-analysis. JGH Open. (2020) 5:107-15. doi: 10.1002/jgh3.12456

18. Bellos I, Lourida P, Argyraki A, Korompoki E, Zirou C, Kokkinaki I, et al. Development of a novel risk score for the prediction of critical illness amongst COVID-19 patients. Int J Clin Pract. (2021) 75:e13915. doi: 10.1111/ijcp.13915
19. Marendić M, Bokan I, Buljan I, Dominiković P, Suton R, Kolčić I. Adherence to epidemiological measures and related knowledge and attitudes during the coronavirus disease 2019 epidemic in Croatia: a cross-sectional study. Croat Med J. (2020) 61:508-17. doi: 10.3325/cmj.2020.61.508

20. Kristić I, Pehlić M, Pavlović M, Kolarić B, Kolčić I, Polašek O. Coronavirus epidemic in Croatia: case fatality decline during summer? Croat Med J. (2020) 61:501-7. doi: 10.3325/cmj.2020.61.501

21. Vukičević D, Polašek O. Optimizing the diagnostic capacity for COVID-19 PCR testing for low resource and high demand settings: the development of information-dependent pooling protocol. J Glob Health. (2020) 10:020515. doi: $10.7189 /$ jogh.10.020515

Conflict of Interest: DP, GL, and OP are scientific advisors to the Government of the Republic of Croatia for COVID-19 response, which had no influence in the decision to prepare the manuscript, its preparation or the selection of the journal where the manuscript would be submitted.

The remaining authors declare that the research was conducted in the absence of any commercial or financial relationships that could be construed as a potential conflict of interest.

Publisher's Note: All claims expressed in this article are solely those of the authors and do not necessarily represent those of their affiliated organizations, or those of the publisher, the editors and the reviewers. Any product that may be evaluated in this article, or claim that may be made by its manufacturer, is not guaranteed or endorsed by the publisher.

Copyright (C) 2021 Primorac, Perić, Matišić, Molnar, Zadro, Vince, Lauc and Polašek. This is an open-access article distributed under the terms of the Creative Commons Attribution License (CC BY). The use, distribution or reproduction in other forums is permitted, provided the original author(s) and the copyright owner(s) are credited and that the original publication in this journal is cited, in accordance with accepted academic practice. No use, distribution or reproduction is permitted which does not comply with these terms. 